\title{
Balkanologie
}

Balkanologie Revue d'études pluridisciplinaires

Vol. IX, n' 1-2 | 2005

Volume IX Numéro 1-2

\section{Richard (Yann), Sanguin (André-Louis), éds., L'Europe de l'Est quinze ans après la chute du Mur, Des pays baltes à l'ex-Yougoslavie}

Paris : L'Harmattan, 2004, $330 \mathrm{p}$.

Patrick Michels

\section{OpenEdition}

Journals

Édition électronique

URL : http://journals.openedition.org/balkanologie/1992

DOI : 10.4000/balkanologie.1992

ISSN : 1965-0582

Éditeur

Association française d'études sur les Balkans (Afebalk)

Édition imprimée

Date de publication : 1 décembre 2005

ISSN : 1279-7952

\section{Référence électronique}

Patrick Michels, « Richard (Yann), Sanguin (André-Louis), éds., L'Europe de l'Est quinze ans après la chute du Mur, Des pays baltes à l'ex-Yougoslavie », Balkanologie [En ligne], Vol. IX, n 1-2 | 2005, mis en ligne le 14 janvier 2010, consulté le 17 décembre 2020. URL : http://journals.openedition.org/balkanologie/ 1992 ; DOI : https://doi.org/10.4000/balkanologie.1992

Ce document a été généré automatiquement le 17 décembre 2020.

(c) Tous droits réservés 


\title{
Richard (Yann), Sanguin (André- Louis), éds., L'Europe de l'Est quinze ans après la chute du Mur, Des pays baltes à l'ex-Yougoslavie
}

Paris : L'Harmattan, 2004, 330 p.

\author{
Patrick Michels
}

\section{RÉFÉRENCE}

Richard (Yann), Sanguin (André-Louis), éds., L'Europe de l'Est quinze ans après la chute du Mur, Des pays baltes à l'ex-Yougoslavie, Paris : L'Harmattan, 2004, $330 \mathrm{p}$.

1 Y. Richard et A.-L. Sanguin passent en revue les quinze années passées depuis la chute du Mur de Berlin. L'ouvrage est divisé en deux thèmes.

2 Le premier traite des héritages: assistons-nous à une rupture d'avec le système soviétique ou à une évolution l'intégrant? L'introduction de M.-C. Maurel nous rappelle que les deux approches ne sont pas incompatibles et que les «héritages du passé sont propres à chacun des territoires concernés ». La première partie concerne les recompositions territoriales. C. Autin analyse la politique des États baltes vis-à-vis des minorités russes. J. Wendt et A. Ilies évoquent les vicissitudes du district de Kaliningrad, ballotté entre Pologne, Lituanie et Russie. Y. Richard se penche sur les changements de la Biélorussie. Il montre bien l'évolution par rapport à l'époque soviétique: il ne s'agit pas d'une rupture dans les dynamiques territoriales ou d'un déclin démographique mais de la poursuite d'une évolution débutée avant la fin de l'URSS. Par contre, le Kazakhstan qu'étudie J. Thorez se caractérise par une évolution et une rupture. 0 . Balabanian nous montre les aléas de la production en électricité en Arménie qui ne bénéficie plus de l'approvisionnement «traditionnel » et ne tire pas le meilleur profit des structures existantes. F. Ardillier-Carras nous présente le 
repositionnement de l'Arménie (qui passe de frontière sud de l'URSS à frontière nord de l'espace arabo-persique) et nous démontre l'absurdité du projet nord-américain de couloir pour « régler » le problème du Karabakh. La comparaison démographique des pays occidentaux avec les pays « ex-communistes » (lesquels sont scindés en ex-URSS et démocraties populaires) qu'opère G.-F. Dumont établit des constatations très intéressantes et montre les divergences qui persistent de chaque côté de l'ex-rideau de fer.

3 La deuxième partie de l'ouvrage traite des espaces, urbains et ruraux, en mutation. I. Amestoy et L. Coudroy de Lille comparent l'habitat stalinien en Pologne et en Russie : les formes architecturales sont différentes tout comme l'est l'imprégnation de l'idéologie. C. Cabanne, P. Fatal et E. Tchistiakova passent en revue les aspects positifs et négatifs de l'héritage soviétique en Russie et mettent en exergue les perceptions différentes, inhérentes à chaque groupe social, de la localisation géographique et de l'âge. Volovgrad, leur sujet d'étude, est une "région test " pour l'implantation des nouveautés (impôts) ainsi que pour son conformisme (musellement). D. Eckert nous donne plusieurs pistes de réflexion sur la quasi-absence de changement de toponymes en Russie, au contraire de ce que l'on a pu observer en Europe centrale et balkanique. I. Brade s'appuie sur les principes idéologiques de la politique économique soviétique pour expliquer le déclin de nombreuses villes. Seules les centres économiques (tissu industriel diversifié, localisation géographique avantageuse, relations formelles et informelles des entrepreneurs économiques avec les élites politiques) sont prospères. M. Schulze évoque la modification des modèles migratoires en URSS. A. Ancuta décrit l'impact des coopératives agricoles de production roumaines sur la société agricole. A. Jezierska-Thole nous alerte sur le patrimoine polonais en danger. Des travaux de conservation/restauration sont à réaliser urgemment.

4 La troisième partie est centrée sur les identités territoriales. J. Radvanyi retrace les territoires perdus et reconquis par la Russie, la perception géographique de son espace, les relations au sein de la CEI dont l'utilité est différemment perçue par les acteurs en présence. V. Kolossov dépeint les relations Ukraine-Russie, les enjeux qu'elles recouvrent et les mythes ré-férents, leviers de l'européanisation des ex-«Petits Russiens ». C. Roux traite des relations moldavo-roumano-transnistriennes et montre que la « nation-État » existe. B. Drweski évoque l'évolution de la société polonaise qui, tout en adoptant les normes dominantes, a conservé les habitudes, structures et valeurs de la précédente période. P. Dostal et J. Markusse, se basant sur les enquêtes d'opinion menées par l'Eurobaromètre, estiment qu'un sentiment pro-européen «est en train d'émerger dans l'opinion publique » des pays post-communistes.

5 Le second thème concerne les pays «ex-yougoslaves ». Dans son introduction, A.-L. Sanguin nous rappelle que les rancoeurs et les ambitions rivales sont les vecteurs de «l'explosion».

6 La première partie est consacrée aux recompositions territoriales. M. Bufon revient sur les difficultés à définir l'Europe centrale (point de rencontre linguistique, culturelle, transfrontalière). Elle s'attarde sur les perceptions des acteurs de l'Eurorégion ( instrument de l'expansionnisme hongrois » pour les Slovaques et les Roumains). La dynamisation de la coopération transfrontalière permet, selon J. Zupancic, l'activation des potentiels locaux. Le soutien de l'État et le renoncement aux prétentions territoriales sont les vecteurs du développement. E. Chaveneau-Le Brun montre, par exemple, que la volonté du gouvernement croate d'intégration à l'Europe s'illustre par 
une collaboration avec le TPI (la mort de F. Tudjman ayant aussi ouvert cette voie). Toutefois, le gouvernement en oublie les conditions sociales. M. Klemencic commet un texte ambitieux sur la transition du communisme au «nettoyage ethnique». Malheureusement les nombreux raccourcis historiques nuisent à la compréhension du discours. A.-L. Sanguin étudie la poche de Goražde. Il montre qu'elle n'est pas viable (situation économique déplorable, axes de communication inexistants).

7 La seconde partie traite des nouvelles identités. À partir de cartes mentales et d'imaginative geography, L. Sakaja nous rend compte de la perception qu'ont les lycéens croates de l'Europe. Notamment, elle nous fait part de l'usage binaire de l'Europe qu'ils se représentent. Utilisant les cartes mentales dessinées par ses interviewés, A. Cattaruzza analyse les représentations spatiales politiques et culturelles des 16-25 ans en Bosnie-Herzégovine. La territorialisation constatée est relativisée du fait d'affinités transfrontalières dissymétriques des éventuels pays d'accueil référents. S. Engelstof, A. Pobric, G. Robinson évoquent l'effort mis en œuvre pour " déserbiser ", " décroatiser " et décommuniser les noms de rues à Sarajevo tout en insistant sur l'histoire et la culture commune aux Bosniaques. 